\title{
ANÁLISE DE CONTROLADORES EM MALHA ABERTA E FECHADA PARA UMA COLUNA PILOTO DE DESTILAÇÃO
}

\author{
C. V. de ARAÚJO'1, R. M. L. OLIVEIRA ${ }^{1}$, R. P. BRITO² \\ ${ }^{1}$ Universidade Federal de Campina Grande, Faculdade de Engenharia Química \\ 2 Universidade Federal de Campina Grande, Departamento de Engenharia Química \\ E-mail para contato: romildo.brito@deq.ufcg.edu.br
}

\begin{abstract}
RESUMO - A modelagem dinâmica de uma coluna de destilação permite prever seu comportamento diante de uma variedade de perturbações. Isso torna a simulação cada vez mais fiel ao que ocorre em uma indústria química/ petroquímica, onde as colunas de destilação chegam a representar de 5 a $8 \%$ do custo total de energia de uma planta, de acordo com Soave e Feliu (2002). Este trabalho simula uma planta piloto de destilação de fabricação Armfield, modelo UOP3CC, analisando seu comportamento em estado estacionário, com o auxílio do software Aspen Plus e em seguida exportando os resultado para o Aspen Dynamics. Sistemas de controle foram testados, adicionando-se controles de nível, fluxo e temperatura ao sistema. O sistema de controle em malha aberta para a temperatura não se mostrou eficiente, ao contrário daquele para malha fechada.
\end{abstract}

\section{INTRODUÇÃO}

A destilação é um dos mais antigos e importantes processos de separação utilizado na indústria química/petroquímica. A literatura, diante de tal fato, refere-se à destilação como sendo "o processo de separação em relação ao qual todos os outros devem ser comparados" (Kister, 1992; Kunesh et al.,1995). De acordo com Humphrey (1995), somente nos Estados Unidos (EUA) existiam cerca de 40.000 colunas de destilação em operação, as quais respondiam por mais de $90 \%$ dos processos de separação e investimento da ordem de U\$\$ 8 bilhões. De acordo com Soave e Feliu (2002), as colunas de destilação nas indústrias são responsáveis por cerca de $3 \%$ da energia total consumida nos EUA.

A modelagem dinâmica de colunas de destilação tem como objetivo final avaliar a estabilidade do processo, quando o mesmo é submetido a perturbações diversas, bem como avaliar a performance de um sistema de controle.

A simulação tem como objetivos fornecer a possibilidade de analisar o sistema, bem como os limites deste e compreensão de um sistema real, além de desenvolvimentos futuros e identificação de problemas.

Os objetivos específicos do trabalho são:

- Simular o sistema etanol/água em regime transiente para uma planta piloto de destilação;

- Implementar as configurações de controle possíveis para a planta;

- Testar as configurações de controle propostas.

\section{MATERIAIS E MÉTODOS}


O software Aspen Plus foi utilizado para simular uma coluna piloto de destilação de fabricação Armfield, modelo UOP3CC, de acordo com a Figura 1 para a separação da mistura água e etanol.

Figura 1. Fluxograma da coluna UOP3CC em regime estacionário.

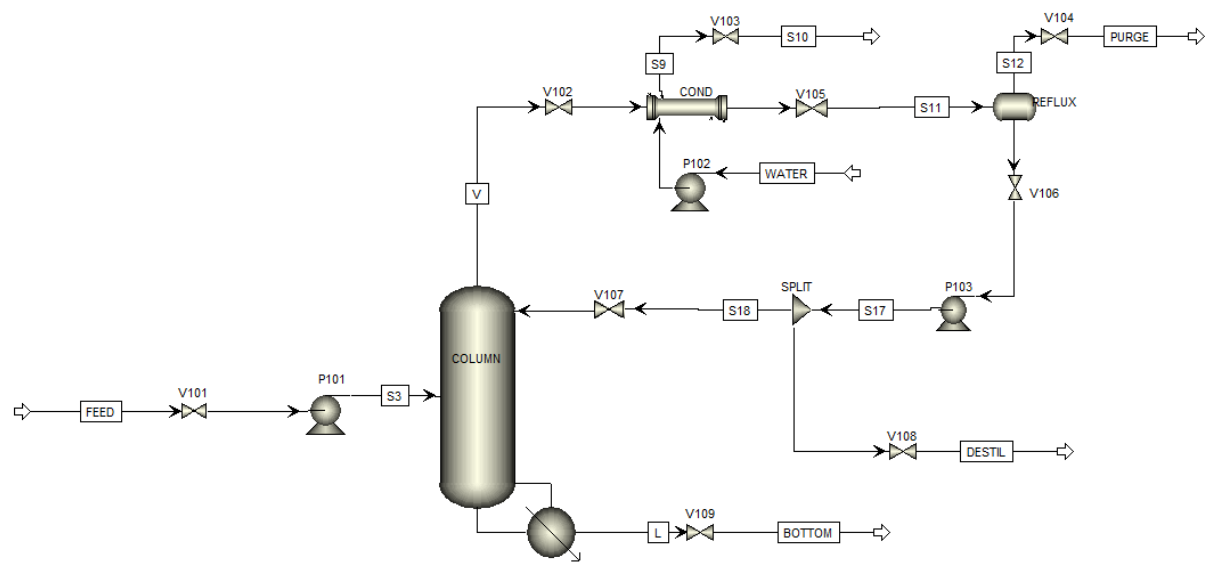

A corrente de alimentação e aquela que alimenta o condensador seguem as especificações da Tabela 1. As especificações da coluna estão expostas na Tabela 2. $\mathrm{O}$ destilado sai da coluna pela corrente de topo $V$ e logo passa pelo condensador COND, ocorrendo uma condensação total da mistura mais rica em etanol. Em seguida, tal mistura passa por um vaso de refluxo REFLUX, onde não se acumula, passando diretamente para o separador SPLIT, de onde parte voltará para a coluna, pelo primeiro estágio, e parte será coletada como destilado, na corrente DESTIL. Acima do vaso de refluxo, há uma corrente de purga PURGE que representa uma abertura de alívio de pressão, existente na coluna piloto presente no laboratório. Do nono estágio da coluna (refervedor), sai uma corrente rica no componente mais pesado (água), BOTTOM.

Tabela 1. Especificações das correntes de alimentação da simulação em estado estacionário.

\begin{tabular}{cccccc}
\hline Componente & Corrente & $\begin{array}{c}\text { Temperatura } \\
\left({ }^{\circ} \mathbf{C}\right)\end{array}$ & $\begin{array}{c}\text { Pressão } \\
(\text { atm) }\end{array}$ & $\begin{array}{c}\text { Fração } \\
\text { Mássica }\end{array}$ & Vazão \\
\hline Água & FEED & 25 & 1 & 0,7 & \multirow{2}{*}{4,0 L.h ${ }^{-1}$} \\
\hline Etanol & FEED & 25 & 1 & 0,3 & \\
\hline $\begin{array}{c}\text { Água de } \\
\text { refrigeração }\end{array}$ & WATER & 25 & 1 & 1,0 & 4,4 L.min ${ }^{-1}$ \\
\hline
\end{tabular}

Tabela 2. Especificações da coluna UOP3CC

\begin{tabular}{cc}
\hline Variáveis & Especificações \\
\hline Número de estágios & 9 \\
\hline Estágio de Alimentação & 5 \\
\hline
\end{tabular}




\begin{tabular}{cc}
\hline Pressão (atm) & 1,0 \\
\hline Queda de Pressão na Coluna (atm) & 0,1 \\
\hline Estágio do Refervedor & 9 \\
\hline Condensador & Não acoplado \\
\hline
\end{tabular}

Os resultados no Aspen Plus foram exportados para o Aspen Dynamics, através do modo Pressure Driven, sem controladores, adicionando-os já no regime transiente.

Os controladores foram adicionados seguindo as especificações do Quadro 1 e como pode ser visualizado na Figura 2. Os parâmetros P.I. utilizados nos controladores de fluxo e de nível foram calculados automaticamente pelo Aspen Dynamics, ao adicioná-los ao sistema. Quanto aos parâmetros P.I.D. do controle de temperatura, esses foram obtidos por experimentos na coluna UOP3CC, sendo o ganho proporcional igual a $1,18 \%$, o tempo integral igual a 15 minutos e o tempo derivativo, 0,3 minutos.

Quadro 1. Controladores utilizados e emparelhamento das variáveis controladas e manipuladas.

\begin{tabular}{|c|c|c|}
\hline Controladores & Variável controlada & Variável Manipulada \\
\hline Controle de Vazão & $\begin{array}{c}\text { Vazão volumétrica de } \\
\text { alimentação }\end{array}$ & $\begin{array}{c}\text { Abertura/Fechamento da } \\
\text { válvula da corrente de } \\
\text { alimentação }\end{array}$ \\
\hline Controle de Nível & Nível do refervedor & $\begin{array}{c}\text { Abertura/Fechamento da } \\
\text { válvula da corrente de saída } \\
\text { da base }\end{array}$ \\
\hline Controle de Temperatura & Temperatura no estágio 8 & Carga térmica do refervedor \\
\hline
\end{tabular}

A simulação foi realizada em malha aberta e malha fechada para a temperatura do estágio 8. Inicialmente, o controlador de temperatura permaneceu em modo manual e provocaram-se distúrbios de $5 \%$ a mais e a menos no setpoint da vazão de alimentação, sempre esperando o sistema estabilizar e voltando ao valor original, $4 \mathrm{~L} . \mathrm{h}^{-1}$, antes do próximo distúrbio e também ao final da simulação. Para a simulação em malha fechada, o controlador de temperatura voltou ao modo automático e repetiram-se os distúrbios na vazão da alimentação. 
Figura 2. Fluxograma da coluna UOP3CC em regime transiente.

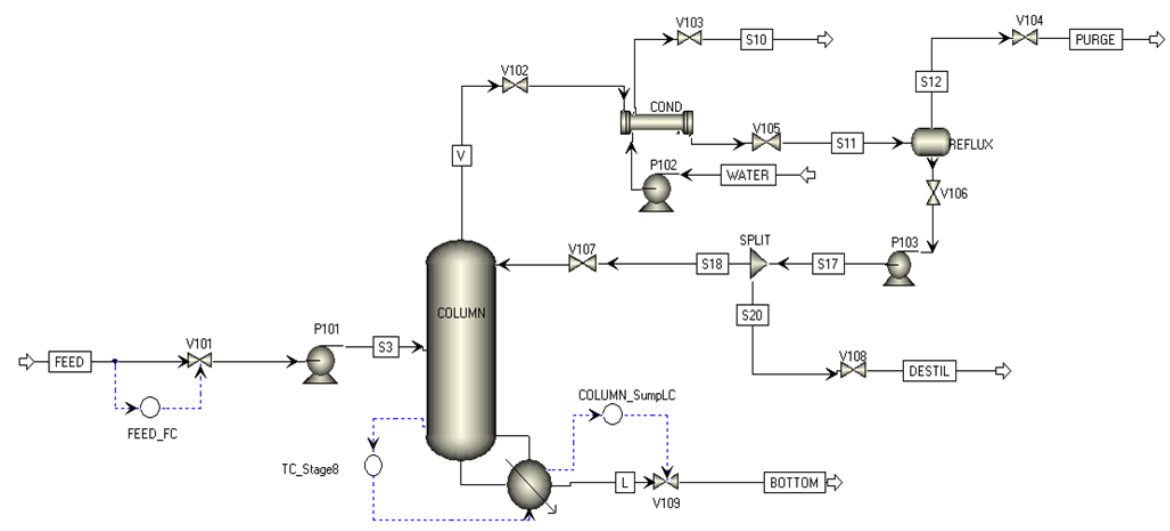

\section{RESULTADOS E DISCUSSÕES}

Percebeu-se que, em malha aberta, o sistema conseguiu manter sua estabilidade durante o primeiro distúrbio, aumentando-se a vazão de 4 para 4,2 L.h ${ }^{-1}$, e o segundo, quando retornou o valor da vazão para 4 L.h ${ }^{-1}$, mantendo-se os valores das variáveis quase que constantes. Todavia, ao se reduzir a vazão para 3,8 L.h-1, por volta das 40 horas de simulação, o sistema passou ficar fora de controle, comportando-se como em um controle on-off. As Figuras 3 (a) e 4 (a) demonstram esse comportamento para as composições de etanol no topo e de água na base da coluna. Isso se deve à sensibilidade da coluna, devido a suas pequenas dimensões.

Figura 3. Gráficos do comportamento da composição de etanol no destilado em malha aberta (a) e fechada (b).

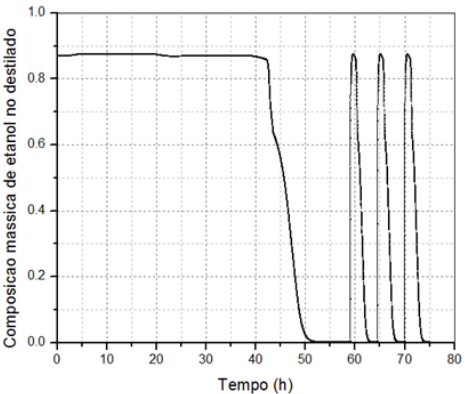

(a)

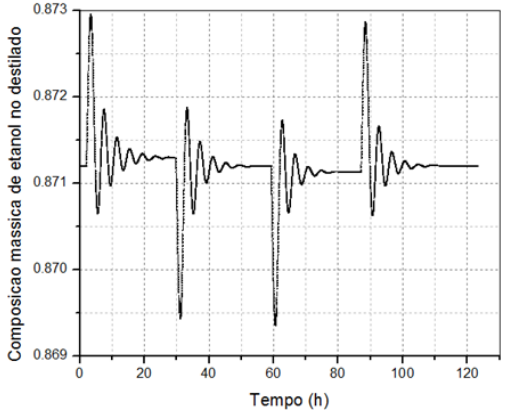

(b) 
Figura 4. Gráficos do comportamento da composição de água na corrente de base da coluna em malha aberta (a) e fechada (b).

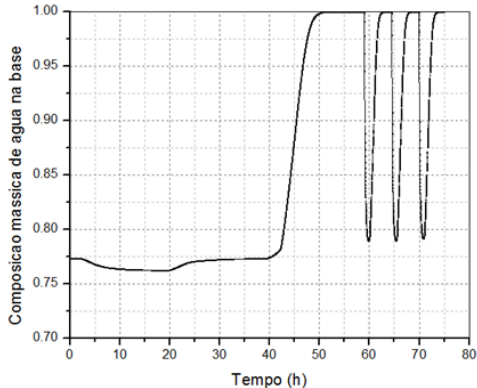

(a)

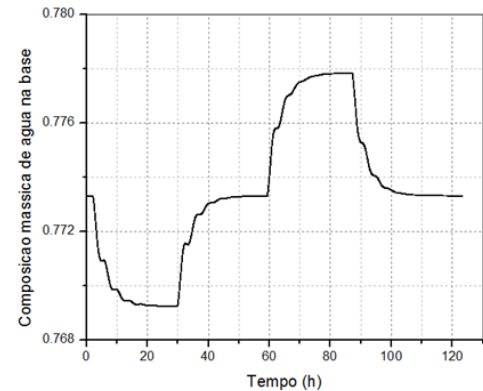

(b)

Durante a simulação em malha aberta, percebeu-se que a válvula V101 foi totalmente aberta pelo controle de fluxo e ainda assim, a vazão de alimentação (Figura 6 (a)) e o nível presente no refervedor chegaram a zero. Como para esta simulação a carga térmica mantevese fixa em $0,5 \mathrm{~kW}$ (Figura 5 (a)), uma explicação para esse fenômeno seria a de que toda a vazão de alimentação foi vaporizada, não chegando a acumular componente mais pesado na base da coluna.

Figura 5. Gráficos do comportamento carga térmica do refervedor em malha aberta (a) e fechada (b).

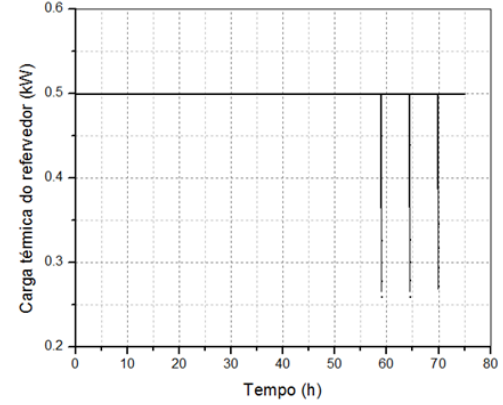

(a)

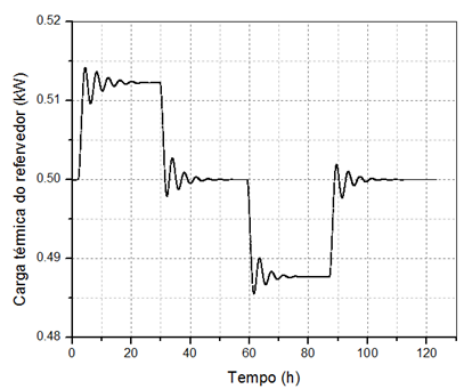

(b)

Figura 6. Gráficos do comportamento da vazão de alimentação em malha aberta (a) e fechada (b).

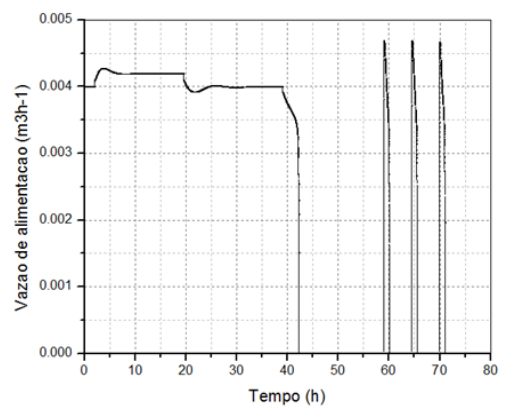

(a)

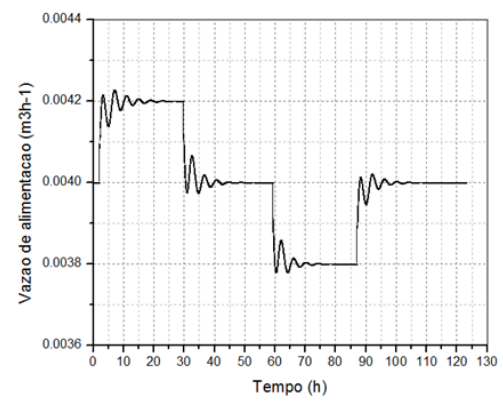

(b) 
Figura 7. Gráficos do comportamento da vazão da corrente de topo da coluna em malha aberta (a) e fechada (b).

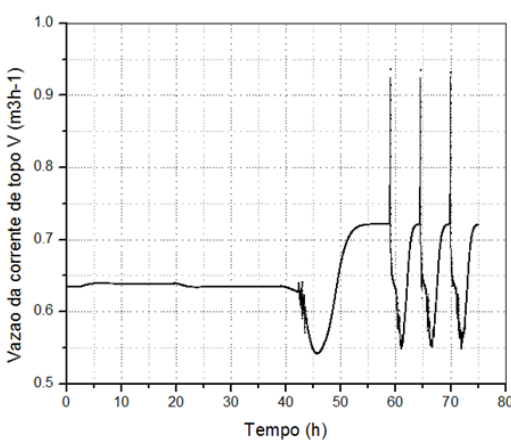

(a)

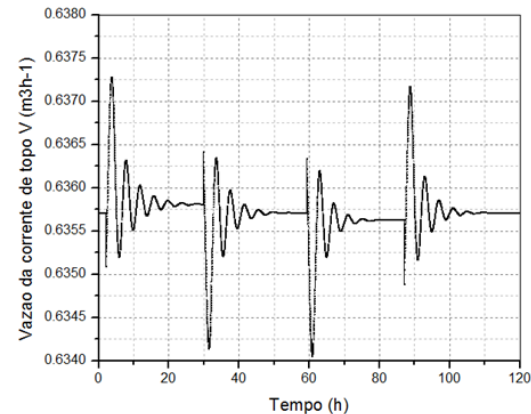

(b)

Como é suposto que toda a mistura está sendo vaporizada, é evidente que a vazão da corrente de topo aumente, o que pode ser constatado na Figura 7 (a). Porém, esse fato não é vantajoso ao sistema, já que também há uma quantidade relevante de água nessa corrente.

Como a carga térmica do refervedor manteve-se fixa e toda a mistura foi vaporizada em malha aberta, isso implicou em um aumento de temperatura ao longo de toda a coluna, o que pode ser comprovado pelo comportamento da temperatura do prato 1, no topo, presente na Figura 8 (a). Isso mostra o quão ineficiente está sendo a separação nessa situação, já que cada vez mais água está chegando ao topo, acumulando-se o mínimo possível na base.

Figura 8. Gráficos do comportamento da temperatura no topo da coluna em malha aberta (a) e fechada (b).

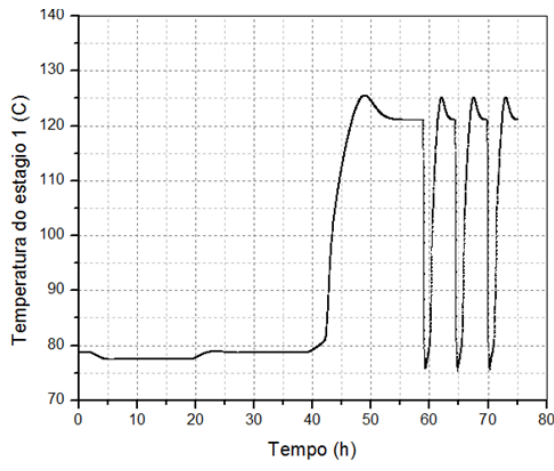

(a)

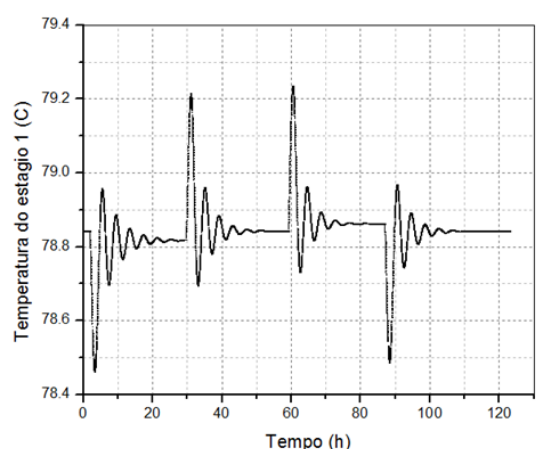

(b)

Para a simulação em malha fechada, percebeu-se uma grande estabilidade no sistema. Apesar dos distúrbios na alimentação, as varáveis mantiveram-se em uma faixa bastante próxima da desejada, com variações quase que desprezíveis. Os gráficos das Figuras de 3 (b) a 8 (b) comprovam isso. Ao se comparar as Figuras de item (a) com as de item (b), observa-se o grande efeito do controle de temperatura para o sistema, o qual variou a carga térmica (Figura 5 (b)) do refervedor a fim de manter a temperatura da base da coluna constante. 


\section{CONCLUSÕES}

Percebeu-se a importância da malha fechada para o controle de temperatura, o qual manteve todo o sistema estável e sob as especificações, alterando o valor da carga térmica do refervedor e mantendo a temperatura na base da coluna com o valor necessário à separação.

\section{REFERÊNCIAS}

KISTER, H.Z. Distillaion Design. McGraw-Hill, Inc. 1992.

KUNESH, J., KISTER, H., Lockett, M., Fair, J. Distillation: Still Towering Over Other Options. Chem. Eng. Progr, 91, 10. 1995.

LUYBEN, W. L. The Impact of Process Diversity on Distillation Column Control, Ind. Eng. Chem. Res., 28. 1987.

SOAVE, G.; FELIU, J. A. Saving Energy in Distillation by Feed Splitting, Applied Thermal Engineering. 2002. 